A.E. Gaidaenko ${ }^{1}$, I.V. Kirgizov ${ }^{1,2}$, A.G. Talalaev ${ }^{1,3}$, K.N. Baranov ${ }^{1,2}$, I.A. Shishkin $^{1,2}$, A.A. Gusev ${ }^{1}$

${ }^{1}$ Scientific Center of Children's Health, RAMS, Moscow

${ }^{2}$ I.M. Sechenov First Moscow State Medical University

${ }^{3}$ N.I. Pirogov Russian National Research Medical University, Moscow

\title{
The Case of Surgical Treatment of a Child With a Doubling of the Ileum
}

\section{Contact information:}

Gusev Aleksei Andreevich, MD, PhD

Address: 119991, Moscow, Lomonosovsky ave.,2/62, phone: 499) 134-02-10

Received: 18.01.2012, accepted for publication: 01.03.2012

This clinical observation was carried out over a teenager at age 17 with long lasting doubling of the ileum, formation of sinus openings in the lumen of the intestine, exhibited by recurrent intestinal bleeding and abdominal pain. Surgery was the only way to effectively treat the child. The indications for surgery were the clinical manifestations of chronic invagination resistant to conservative treatment. Key words: the terminal ileum doubling, chronic intestinal invagination, intestinal bleeding, children.

Intestinal duplication is a rare congenital pathology. There are several theories of the digestive duplication embryogenesis. Some duplications of an ileum or a large intestine may be a part of "incomplete general" duplications. The spectrum of deformations varies from a complete duplication of the underpinning and limbs (dipygus) to a regular "isolated" duplication of the embryonal hindgut structures. According to the other theory, the reason for the duplication development is the split notochord syndrome. In that case enteric duplication is the residual remain of a neuroendocrinal meatus. Regression malfunction of the latter also results in a complete dorsal enteric fistula, bridle through the spinal cord (diastematomyelia), intraspinal cyst, dorsal enteric sinus, neuroenteric cyst and an enteric duplication 
itself. There is also a theory of the digestive duplication development from the embryo's intestinal diverticula. And finally, duplication development may be a result of an intestinal recanalization after a considerable stage of the embryonal development.

Given observation shows a tubular ileal duplication with the appearance of multiple sinus openings connecting both lumina as a result of a protracted inflammation.

Adolescent S., 17 years old, was admitted to a gastroenterology unit of the research institute for pediatrics at the FSBI RAMS "Scientific Centre of Children's Health" for the first time in November 2011 with the diagnosis "Noninfectious enterocolitis of unknown etiology" and after 2 days was transferred to the surgical department on suspicion of a chronic intussusception.

It becomes known from the anamnesis that at the age of 10 the child experienced abdominal pains for the first time. In the hospital at the place of residence an acute destructive mesenteric lymphadenitis, catarrhal appendicitis were diagnosed. Appendectomy was conducted. In 2009 at the age of 15 abdominal pains recurred, sharpening by 2010. In the hospital at the place of residence chronic gastritis was diagnosed. Despite treatment, the pains remained. Adolescent was sent to the regional children's clinical hospital (RCCH), where peritoneal symptoms were revealed at admission. Diagnostic laparoscopy was conducted, fixation of the head of blind colon to the scar was revealed, a hematoma between the commissurae; in 2 days laparoscopic sanitation was conducted. On the $7^{\text {th }}$ postoperative day tarry stool and hemoglobin fall to $90 \mathrm{~g} / \mathrm{l}$ were observed. Source of bleeding was not found. Ultrasonography data indicated a persistent infiltrate in the right iliac region, fragment of the immobile bowel with walls thickened to $2.5-3 \mathrm{~mm}$, lymph nodes were detected $(14 \times 7 \mathrm{~mm})$. Given the bowel's condition in the ileocical region (walls' thickening, bleeding), it was decided to prescribe $1.5 \mathrm{~g} /$ day Salofalk. 
In one year, in February, then in April, May and August 2011 abdominal pains recurred with tarry stool in their setting. Adolescent was examined in the $\mathrm{RCCH}$, where the $2^{\text {nd }}$-grade reflux-esophagitis, gastroesophageal reflux, gastroduodenitis, cardia polyp, polyp in the perianal area and frank chronic colitis were diagnosed. Hemoglobin level fell to $68 \mathrm{~g} / \mathrm{l}$, although the source of bleeding was not found. Ultrasonic abdominal examination detected waxing kernels (36x11 $\mathrm{mm}$ and 32x12 mm) in the right hypogastrium, intestinal loops in the lower right segments with walls thickened to $2 \mathrm{~mm}$ and free fluid in the pelvis minor and laterals. Celiac trunk triplex scanning, fibrogastroduodenoscopy, scintiangiography, ultrasonography of the urinoexcretory system organs, computed tomography and magnetic resonance imaging were conducted - pathology not found.

Infectious nature of the reactive changes in the intestines was not proved either.

In November 2011 the child was sent to a gastroenterology unit of the RAMS SCCH. Upon acute abdominal pains' recurrence the abdominal cavity ultrasonography was conducted: colonic intussusception, straightened during the succeeding colonoscopy, was suspected. Child transferred to the surgical department. Severity level of the child's condition at admission was considered moderate. Colicky pains in the left iliac region remained. No nausea, no emesis. Body temperature $-36.6^{\circ} \mathrm{C}$. Weight $-54.5 \mathrm{~kg}$, height $-177 \mathrm{~cm}$. Malnutrition; pink, clean cutaneous coverings. Anteroventral scars after appendectomy and laparoscopy - in satisfactory condition. Abdomen - symmetrical, not swollen, took part in breathing. Liver - by the edge of the costal margin. Peristalsis auscultable, of regular intensity. Abdomen - soft on palpation, painful in the left iliac region. No peritoneal symptoms. Flatus discharge. Stool - regular, solid, brown, without pathological admixtures. Urination - unassisted, diuresis adequate. 
As far as after the intussusceptum endoscopic straightening pains in the left iliac region remained it was decided to conduct a diagnostic laparoscopy with the subsequent decision, if necessary, on the amount of operative intervention on the surgical table.

Child was prescribed hunger, spasmolytics and cleansing enemata.

Operation course. Under intubation anesthesia, after double scrubbing and surgical site sanitization, a video camera with "Chameleon" optics was administered by the single-port access by the lower navel semi-circumference with the help of "X-cone" trocar. Abdominal cavity was examined down the small intestine in the small pelvis area. An altered ileum was revealed at $60-70 \mathrm{~cm}$ level off the ileocecal angle, altered for over $40 \mathrm{~cm}$, tightly knit together with the fundus of bladder. Conglomeration separation did not seem possible laparosopically, which is why the Pfannenstiel incision through the mini-laparotomy incision was conducted. Soft tissues were cut by an incision up to $5 \mathrm{~cm}$ in the pubic region, abdominal cavity - dissected. Ileum inflamed conglomeration separation was conducted, rupture segment - tightly knit with the bladder wall, bladder wall non-mutilated and intact. In the course of the altered iliac wall revision its congenital anomaly was revealed - duplication (pic. 1).

The length of the duplicated segment was identified with the help of the "Nelaton" catheter. Resection of the altered part of the ileum with the overall length of ca. $40 \mathrm{~cm}$ in the limits of sound tissues was conducted. Abdominal cavity was sanitized, drained through the puncture in the right subcostal area with the tubular silicon drainage with active aspiration. Single-port access and laparotomy wound was sutured up. Stitches were put on the skin. Aseptic dressing.

On the $2^{\text {nd }}$ day the child was transferred from the resuscitation department to the surgical department. Early postoperative period progressed without any peculiarities.

The child remained on total parenteral nutrition for 4 days with a subsequent gradual increase in the amount of interal feeding. The Levin tube was removed on 
the $2^{\text {nd }}$ postoperative day. No emesis, the amount of nutrition injected was digested. Allowed to sit on the $3^{\text {rd }}$ day, to walk - on the $5^{\text {th }}$ day. Surgical drain has also removed from the abdominal cavity on the $5^{\text {th }}$ day.

On the $12^{\text {th }}$ postoperative day the child was discharged in satisfactory condition. No postoperative complications.

In the course of revision and examination of the gross specimen of the removed segment of the small intestine an ileal duplication together with the appearance of sinus openings and the altered segment of the small intestine rupture segment, intimately connected with the bladder wall, were revealed (pic. 2).

According to the histologic study, a diffuse neuroendocrinal hyperplasia was revealed in the altered segment of the small intestine. Yet, the mucous tunic of the unaltered segment had a normal structure (pic. 3).

Thus, the reason of the recurrent enterorrhagiae with the occasional abdominal pains was the chronic intussusception, the anatomic precondition of which was the tubular ileal duplication and fixation of the ileum segment to the bladder wall.

\section{Reference list}

1. Lenyushkin A.I. Khirurgicheskaya koloproktologiya detskogo vozrasta. Moskva: Meditsina. 1999. S. 122-127.

2. Kholostova V.V. Udvoeniya zheludochno-kishechnogo trakta. V kn.: Detskaya khirurgiya. Natsional'noe rukovodstvo / pod red. Yu.F. Isakova, A.F. Dronova. M.: GEOTAR-media. 2009. S. 375-379.

3. Zachariou Z. Pediatric Surgery Digest. Springer-Verlag Berlin Heidelberg. 2009. R. 417-422.

4. Gross R.E. The Surgery of Infancy and Childhood. WB Saunders. Philadelphia. 1953. R. 221-245.

5. Wrenn E.L. Alimentary tract duplications. In: K.W. Ashcraft, T.M. Holder eds. Pediatric surgery, 2nd ed. Philadelphia: WB Saunders. 2003. R. 421-433. 
6. Bond S.J., Groff D.B. Gastrointestinal duplication. In: J.A. Jr. O’Neill, M.I. Rowe, J.L. Grosfeld et al. eds. Pediatric surgery, 5th ed. St. Louis. MO: Mosby-Year Book. 2008. R. 1257-1267.

7. Aiken J. Intestinal Duplication. In: K.T. Oldham, P.M. Colombani, R.P. Foglia. Principles and practice of pediatric surgery. Lippincott Williams and Wilkins. 2005; 2: 1329-1343.

Pic. 1. Intraoperative duplicated ileum segment photograph

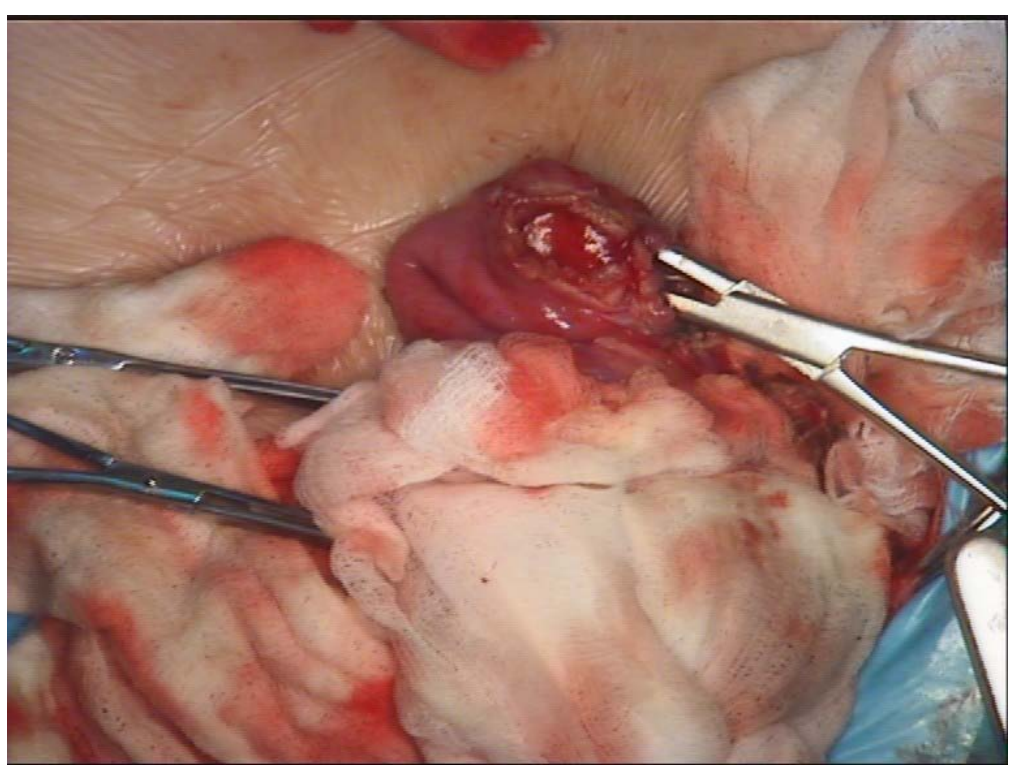


Pic. 2. Removed ileum segment gross specimen. A - before the ileal lumen dissection (arrows show the sinus openings connecting both lumina); B - partly dissected ileal lumen, intestine segment knit to the bladder wall are seen (forceps administered in the lumen of the duplicated ileum segment)
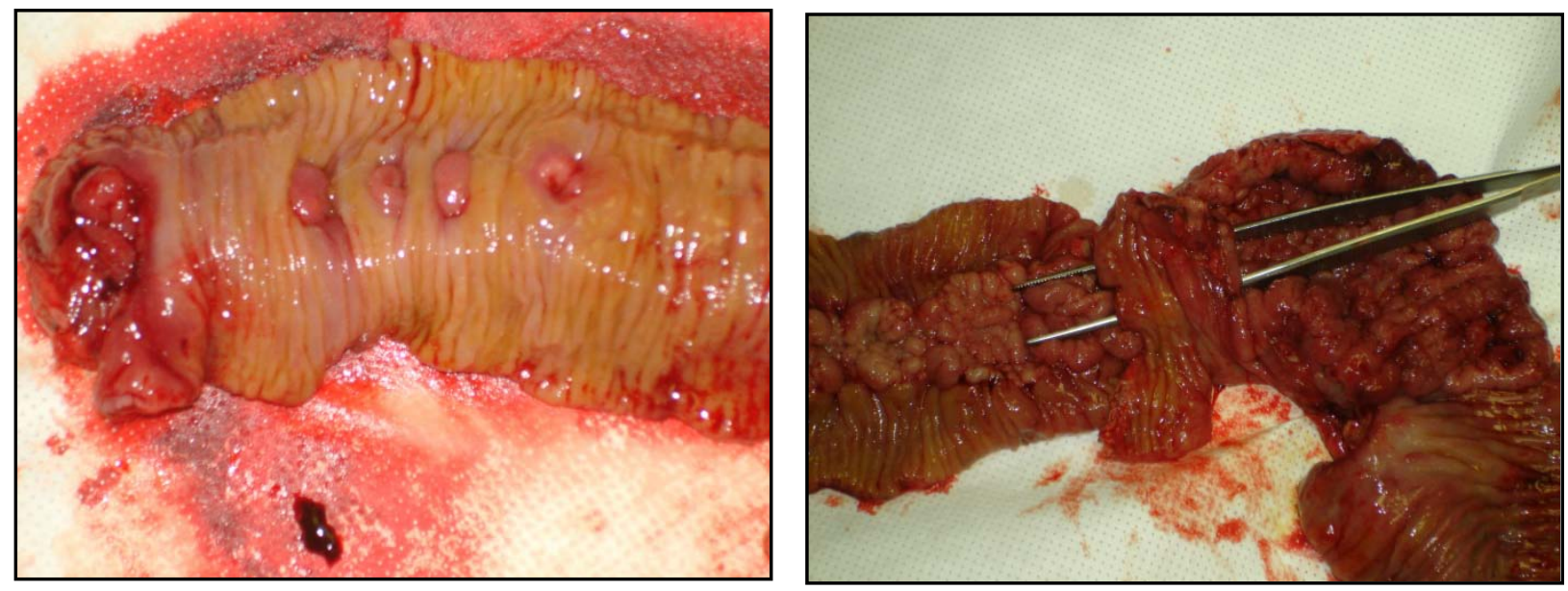
Pic. 3. Microphotographs of the ileal mucous tunic. A - ileum duplicated segment (hematoxylin and eosin stain, magnified x200); B - ileum duplicated segment submucous layer (hematoxylin and eosin stain, magnified x400).

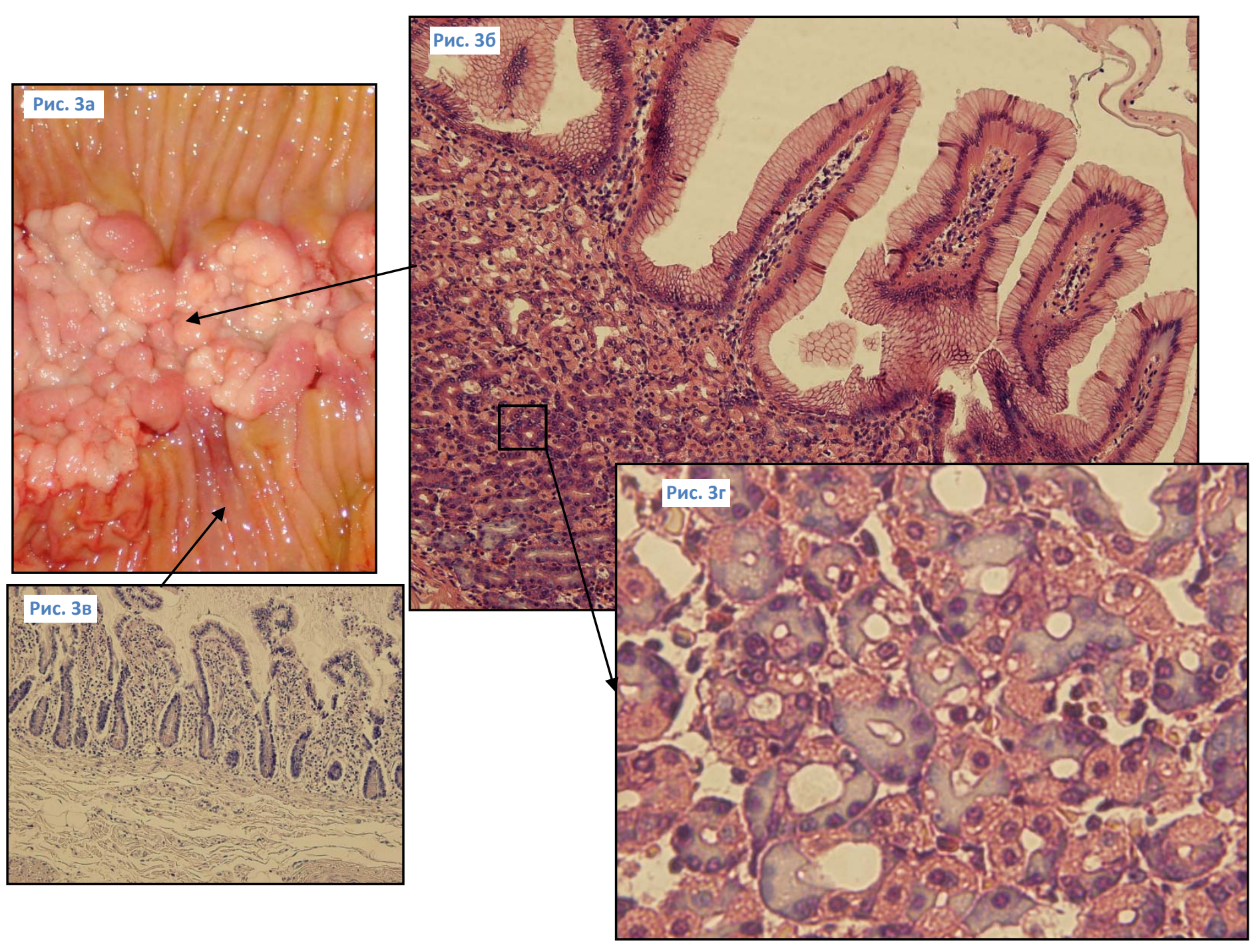

